\title{
METODE SPRINGATE DALAM ANALISA POTENSI KEBANGKRUTAN PERUSAHAAN PROPERTIDI INDONESIA
}

\author{
${ }^{1}$ Murviana Koto, ${ }^{2}$ Delyana Rahmawany Pulungan, ${ }^{3}$ Tri Hartini \\ ${ }^{1,2,3}$ FakultasEkonomi dan Bisnis UniversitasMuhammadiyah Sumatera Utara, \\ Medan, \\ Email : ${ }^{1}$ murvianakoto@umsu.ac.id
}

\begin{abstract}
ABSTRAK
Penelitian ini menggunakan analisis deskriptif terhadap 10 perusahaan Properti yang terdaftar di Bursa Efek Indonesia (BEI). Tujuan penelitian ini adalah untuk mengetahui kondisi kesehatan perusahaanberdadsarkan analisis potensi kebangkrutan. Metode yang digunakan dalam Analisa potensi kebangkrutan ini adalah metodeSpringate. Hasil penelitian ini menunjukkan bahwa dari 10 perusahaan yang diteliti, 8 perusahaan mengalami kesulitan keuangan dan berada dalam area berpotensi mengalami kebangkrutan.
\end{abstract}

Kata Kunci : Potensi kebangkrutan, Metode Springate

\section{ABSTRACT}

This study uses descriptive analysis of 10 property companies listed on the Indonesia Stock Exchange (IDX). The purpose of this study was to determine the health condition of the company based on an analysis of potential bankruptcy. The method used in this analisis is the potential for bankruptcy by Springate method. The results of this study indicate that 10 of the 8 companies studied had financial difficulties and were in the area of potential bankruptcy.

Keywords: Potential bankruptcy, Springate Method

\section{PENDAHULUAN}

Pertumbuhan sektor properti sangat sensitif terhadap indikator makro ekonomi, dan proyek pembangunan properti dapat mencetak banyak lapangan pekerjaan dan menggerakkan berbagai industri lainnya. Sektor ini juga menjadi salah satu indikator penting untuk menganalisis kesehatan ekonomi suatu negara, karena dapat memberi sinyal sedang jatuh atau sedang berkembangnya perekonomian sebuah negara (Koto: 2015; Santoso: 2005).

Sektor properti juga telah menghantarkan Amerika Serikat menghadapi krisis finansial pada tahun 2007, ketika pemerintah Amerika Serikat memperbesar porsi kredit kepada masyarakat yang seharusnya tidak tepat untuk mendapatkan kredit perumahan dari perbankan sehingga mengakibatkan meluasnya kredit macet dan terjadinya

subprimemortagesecurities. 
Permasalahan ini memberikan efek domino bagi banyak perusahaanperusahaan di dunia, sehingga mengalami kesulitan keuangan (financialdistress) bahkan kebangkrutan. Permasalahan ini membesar sehingga menyebabkan terjadinya krisis bagi banyak negara di dunia termasuk Indonesia.

Kebangkrutan merupakan masalah yang sangat mendasar yang harus diwaspadai oleh perusahaan bahkan oleh negara. Karena ancaman kebangkrutan dapat dialami setiap perusahaan, baik perusahaan kecil maupun perusahaan besar dan dapat memberiakn efek yang meluas. Analisis kebangkrutan dilakukan untuk memperoleh peringatan awal kebangkrutan (tanda-tanda bangkrut).Semakin dini tanda-tanda kebangkrutan dapat terdeteksi, akan semakin baik bagi pihak manajemen agar dapat mengantisipasi dan membuat strategi dalam melakukan perbaikan agar kebangkrutan tersebut tidak terjadi.

Bagi investor, $\begin{array}{r}\text { Pemahaman } \\ \text { kebangkrutan }\end{array}$
tentang potensi
sangatlah penting sebagai dasar
dalam pengambilan keputusan dalam
berinvestasi. Investor diharapkan
tidak salah dalam memilih
perusahaan yang akan menjadi
tempat investasi. Selain investor,
pemahaman teori potensi
kebangkrutan juga harus dimiliki
oleh manajemen perusahaan, dengan
pemahaman yang baik atas potensi
kebangkrutan maka perusahaan bisa
mengantisipasi segala kemungkinan
yang akan membawa perusahaan
tersebut ke dalam rona
kebangkrutan. Kesalahan dalam
pengambilan keputusan oleh
manajemen perusahaan, dan

tingginya hutang perusahaan dapat menjadi penyebab yang dapat membawa perusahaan pada kebangkrutan (Rudianto, 2013).

Ada berbagai cara yang dapat digunakan dalam menganalisis potensi kebangkrutan, dan analisis model Springate, Zmijewski, dan Altman Z-Score merupakan model analisis kebangkrutan yang paling sering digunakan dan dikenal luas, karena memiliki cara yang relatif mudah dan dapatmemprediksi kebangkrutannya dengan cukup akurat. Ketiga model ini dikembangkan dan dibentuk melalui perbandingan rasio-rasio keuangan dalam mengidentifikasi hasil akhir dari prediksi kebangkrutan.Namun, ketiga model tersebut memiliki kelemahan dan kelebihan masingmasing dalam penentuan modelnya.

Penelitian ini menggunakan metode Springate dalam menganalisis potensi kebangkrutan pada perusahaan property yang terdaftar di bursa efek Indonesia. Springate adalah model untuk memprediksi keberlangsungan hidup suatu perusahaan dengan mengkombinasikan beberapa rasio keuangan yang umum dengan diberikan bobot yang berbeda satu dengan yang lainnya (Rudianto, 2013). Metode Sringate menggunakan empat rasio keuangan yang digunakan untuk menghitung model, yaitu Working Capital to Total Asset (yaitu ukuran aset lancar bersih yang berkaitan dengan modal kerja), Earning Before Interest And 
Taxes (yaitu produktivitas sesungguhnya dari asset perusahaan terlepas dari adanya faktor pajak maupun bunga), EarningBeforeTaxestoCurrentLiabili ties (yaitu kemampuan perusahaan membayar hutang lancar dengan laba yang telah dipotong dengan pajak), dan Salesto Total Assets (yaitu kemampuan aset perusahaan dalam menghasilkan laba dari hasil penjualan). Metode Springate dalam menganalisis potensi kebangkrutan dipilih karena model ini memiliki tingkat akurasi 92,5\% (Springate: 1978).

Rumusanmasalahpadapenelitianin iadalahbagaimanakahkinerjakeuanga ndanpotensikebangkrutandari $\quad 10$ perusahaanproperti yang terdaftar di Bursa Efek Indonesia?

\section{Literature}

Kebangkrutan dapat diartikan sebagai kegagalan perusahaan dalam menjalankan operasi perusahaan untuk menghasilkan laba. Menurut Toto (2011), kebangkrutan (bankcruptcy) merupakan kondisi dimana perusahaan tidak mampu lagi untuk melunasi kewajibannya. Kondisi ini biasanya tidak muncul begitu saja diperusahaan, ada indikasi awal dari perusahaan tersebut yang biasanya dapat dikenali lebih dulu kalau laporan keuangan dianalisis secara lebih cermat dengan suatu cara tertentu. Faktor-faktor internal yang bisa menyebabkan kebangkrutan perusahandiantaranya adalah manajemen yang tidak efisien dalam menjalankan perusahaan dan mengakibatkan kerugian terusmenerus yang pada akhirnya menyebabkan perusahaan tidak mampu membayar kewajibannya. Ketidakefisienan ini diakibatkan oleh pemborosan dalam biaya, kurangnya keterampilan, dan keahlian manajemen (Darsono, 2005). Menurut Gunardiansya (2009), ada beberapa penyebab kebangkrutan, diantaranya: 1) Kegagalanekonomi(EconomicFail ure). Kegagalan ini terjadi karena biaya operasional perusahaan lebih besar dari pendapatannya. 2) Kegagalankeuangan(FinancialDistre ssed). Perusahaan yang dinyatakan mengalami kegagalan keuangan, baik dalam pengertian kas atau dalam pengertian modal kerja.3) Insolvensiteknis(TecnhcalInsolvenc y). Insolvensi teknis adalah kegagalan perusahaan dalam menjalani teknis/ketentuan kewajiban yang berlaku. Perusahaandianggap gagal jika perusahaan tidak dapat memenuhi kewajiban pada saat jatuh tempo,walaupun perusahaan memiliki total aset yang melebihi total utang. 4) Insolvensikebangkrutan. Kondisi dimana nilai sekarang dari arus kas yang diharapkan lebih rendah dari liabilitas yang dimiliki. 5) LegalBankruptcy. Perusahaan dinyatakan bangkrut secara hukum, 
dan dinyatakan secara resmi oleh undang-undang dan peradilan.

Model Springate yang dikenal untuk memprediksi kebangkrutan perusahaan di masa-masa mendatang dengan melihat dari sisi laporan keuangan, dapat digunakan sebagai suatu sarana bagi pihak- pihak yang berkepentingan dalam menganalisis dan mengevaluasi kondisi dan kinerja satu atau beberapa perusahaan. Penelitian yang dilakukan oleh Gordon L.V Springate (1978) menghasilkan model prediksi kebangkrutan yang dibuat dengan mengikuti prosedur model Altman Z-Score.

Model Springate menggunakan empat rasio keuangan yang dipilih berdasarkan 19 rasio-rasio keuangan dalam berbagai literatur. Springate (1978) merumuskan model perhitungannya sebagai berikut:

$S=1,03 X_{1}+3,07 X_{2}+0,66 X_{3}+$ $0,4 X_{4}$

Keterangan :

$X_{1}=$ Working Capital / Total Asset

$\begin{array}{rlr}X_{2} & =\quad \text { Net Profit } \\ & \text { BeforeInterestandTaxes } \\ & \text { Total Assets } \\ X_{3} & =\text { Net Profit } & \text { BeforeTaxes / } \\ & \text { Current } \quad \text { Liabilities } \\ X_{4} & =\text { Sales / Total Asset }\end{array}$

Dengan kriteria penilaian apabila nilai $\mathrm{Z}>0,862$ maka menunjukkan indikasi-indikasi perusahaan menghadapi ancaman kebangkrutan yang serius (bangkrut), apabila nilai $0,862<\mathrm{Z}<1,062$ maka menunjukkan bahwa pihak manajemen harus hati-hati dalam mengelola aset-aset perusahaan agar tidak terjadi kebangkrutan (daerah rawan). Dan apabila nilai $Z>1,062$ maka menunjukkan perusahaan dalam kondisi keuangan yang sehat dan tidak mempunyai permasalahan dengan keuangan (tidak berpotensi bangkrut).

\section{METODOLOGI PENELITIAN}

Penelitian ini merupakan penelitian deskriptif kuantitatif, yaitu dengan cara mengumpulkan, mengklasifikasikan, menganalisisis dan menginterpretasikan data-data yang diperoleh dari perusahaan sehingga dapat memberikan gambaran dengan keadaan yang sebenarnya. Penelitian ini bersifat empiris, dimana dilakukan pada perusahaan properti periode 20122016 yang terdaftar di Bursa Efek Indonesia (BEI) melalui situs resmi Bursa Efek Indonesia (www.idx.co.id), dan diperoleh 10 perusahaan yang dijadikan sampel pada penelitian ini.

\section{HASIL PENELITIAN DAN PEMBAHASAN}

A. Net Working Capital to Total Aset (Modal Kerja/ Total Aset)

Rasio ini dihitung dengan membagi modal kerja bersih dengan total 
Prosiding Seminar Nasional Multidisiplin Ilmu Universitas Asahan 2018

Tema : "Strategi Membangun Penelitian Terapan yang Bersinergi dengan Dunia Industri, Pertanian dan Pendidikan dalam Meningkatkan Daya Saing Global"

06 November 2018, Kisaran

aktiva. Modal kerja bersih diperoleh dengan cara aktiva lancar dikurangi

Tabel1. TabelPerhitunganSpringate

\begin{tabular}{lrrrr}
\hline Tahun & X1 & X2 & X3 & X4 \\
\hline ASRI & & & & \\
\hline 2012 & $-0,211$ & 0,123 & 0,216 & 0,223 \\
\hline 2013 & $-0,436$ & 0,075 & 0,119 & 0,255 \\
\hline 2014 & $-0,435$ & 0,082 & 0,131 & 0,215 \\
\hline 2015 & $-0,502$ & 0,041 & 0,627 & 0,149 \\
\hline 2016 & $-0,491$ & 0,029 & 0,045 & 0,135
\end{tabular}

ELTY

\begin{tabular}{rrrrr}
\hline 2012 & $-0,147$ & $-0,048$ & $-0,121$ & 0,192 \\
\hline 2013 & $-0,192$ & $-0,003$ & $-0,006$ & 0,270 \\
\hline 2014 & 0,104 & 0,037 & 0,075 & 0,109 \\
\hline 2015 & 0,145 & $-0,001$ & $-0,001$ & 0,095 \\
\hline 2016 & 0,074 & $-0,001$ & $-0,002$ & 0,120
\end{tabular}

BKDP

\begin{tabular}{rrrrr}
\hline 2012 & 0,030 & $-0,063$ & -0.227 & 0,015 \\
\hline 2013 & $-0,018$ & $-0,068$ & $-0,226$ & 0,013 \\
\hline 2014 & 0,007 & 0,018 & 0,064 & 0,130 \\
\hline 2015 & $-0,006$ & $-0,036$ & $-0,129$ & 0,076 \\
\hline 2016 & $-0,242$ & $-0,034$ & $-0,112$ & 0,067
\end{tabular}

\begin{tabular}{lrrrr}
\hline DILD & & & & \\
\hline 2012 & $-0,243$ & 0,045 & 0,129 & 0,207 \\
\hline 2013 & $-0,278$ & 0,054 & 0,117 & 0,201 \\
\hline 2014 & $-0,230$ & 0,059 & 0,116 & 0,204 \\
\hline 2015 & $-0,252$ & 0,041 & 0,075 & 0,214 \\
\hline 2016 & $-0,317$ & 0,025 & 0,044 & 0,192 \\
\hline KPIG & & & & \\
\hline 2012 & $-0,077$ & 0,058 & 0,304 & 0,150 \\
\hline 2013 & $-0,052$ & 0,046 & 0,271 & 0,080 \\
\hline 2014 & $-0,045$ & 0,044 & 0,227 & 0,102 \\
\hline 2015 & 0,001 & 0,024 & 0,116 & 0,102 \\
\hline 2016 & 0,175 & 0,126 & 0,618 & 0,067 \\
\hline
\end{tabular}

dengan kewajiban lancar.

\begin{tabular}{lrrrr}
\hline Tahun & X1 & X2 & X3 & X4 \\
\hline LPCK & & & & \\
\hline 2012 & 0,271 & 0,011 & 0,188 & 0,446 \\
\hline 2013 & 0,291 & 0,119 & 0,224 & 0,392 \\
\hline 2014 & 0,469 & 0,219 & 0,575 & 0,425 \\
\hline 2015 & 0,446 & 1,032 & 3,066 & 0,402 \\
\hline 2016 & 0,562 & 0,097 & 0,389 & 0,403 \\
\hline BKSL & & & & \\
\hline 2012 & 0,123 & 0,040 & 0,185 & 0,101 \\
\hline 2013 & 0,271 & 0,060 & 0,169 & 0,090 \\
\hline 2014 & $-0,001$ & $-0,006$ & 0.018 & 0,057 \\
\hline 2015 & $-0,036$ & 0,002 & 0.013 & 0,014 \\
\hline 2016 & $-0,015$ & 0,013 & 0,133 & 0,043 \\
\hline COWL & & & & \\
\hline 2012 & $-0,135$ & 0,048 & 0,032 & 0,175 \\
\hline 2013 & $-0,282$ & 0,039 & 0,125 & 0,170 \\
\hline 2014 & $-0,518$ & 0,057 & 0,109 & 0,154 \\
\hline 2015 & $-0,504$ & $-0,050$ & 0,114 & 0,165 \\
\hline 2016 & $-0,487$ & 0,004 & 0,100 & 0,163 \\
\hline BSDE & & & & \\
\hline 2012 & 0,092 & $-0,048$ & 0,272 & 0,222 \\
\hline 2013 & 0,082 & $-0,003$ & 0,358 & 0,254 \\
\hline 2014 & 0,049 & 0,037 & 0,440 & 0,200 \\
\hline 2015 & 0,079 & $-0,001$ & 0,169 & 0,172 \\
\hline 2016 & 0,063 & $-0,001$ & 0,148 & 0,170 \\
\hline EMDE & & & & \\
\hline 2012 & 0,148 & 0,013 & 0,032 & 0,123 \\
\hline 2013 & 0,162 & 0,051 & 0,125 & 0,240 \\
\hline 2014 & 0,050 & 0,053 & 0,109 & 0,264 \\
\hline 2015 & 0,019 & 0,051 & 0,114 & 0,272 \\
\hline 2016 & 0,047 & 0,049 & 0,100 & 0,242 \\
\hline & & & & \\
\hline B & & & & \\
\hline 2010
\end{tabular}

Tabel 2. Hasil Perhitungan Model Springate

\begin{tabular}{lllllllllll}
\hline Kode & 2012 & 2013 & 2014 & 2015 & 2016 Kode & 2012 & 2013 & 2014 & 2015 & 2016 \\
\hline ASRI & 0,392 & $-0,051$ & $-0,024$ & $-0,291$ & $-0,333$ ELTY & $-0,302$ & $-0,103$ & 0,361 & 0,250 & 0,153 \\
\hline
\end{tabular}




\begin{tabular}{llllllllllll}
\hline Kode & 2012 & 2013 & 2014 & 2015 & 2016 Kode & 2012 & 2013 & 2014 & 2015 & 2016 \\
\hline BKDP & $-0,313$ & $-0,371$ & 0,157 & $-0,171$ & $-0,191$ BKSL & 0,416 & 0,611 & 0,015 & $-0,017$ & 0,129 \\
\hline DILD & 0,056 & 0,037 & 0,103 & 0,002 & $-0,143$ COWL & 0,100 & $-0,020$ & $-0,225$ & $-0,531$ & 0,645 \\
\hline KPIG & 0,359 & 0,299 & 0,280 & 0,192 & 1,002 BSDE & 0,257 & 0,438 & 0,534 & 0,265 & 0,233 \\
\hline LPCK & 0,615 & 0,970 & 1,705 & 5,772 & 1,295 EMDE & 0,263 & 0,502 & 0,392 & 0,360 & 0,362 \\
\hline
\end{tabular}

\section{B. PEMBAHASAN}

\section{Analisa danPembahasan}

Berdasarkan analisis laporan keuangan pada 10 perusahaan property yang dilakukan dengan menggunakan metode Springate selama lima tahun. Hasil perhitungan menunjukkan bahwaperusahaan 8 perusahaan berada di area berpotensi bangkrut disetiap tahunnya. Yaitu pada perusahaan dengan kode saham ASRI, ELTY, BKDP, DILD, BKSL, COWL, BSDE dan EMDE. Permasalahan ini disebabkan karena pada variabel Springate $\mathrm{X}_{1}$ NWCTA (modal kerja terhadap total aset) pada rasio ini yang dimiliki Alam Sutera Realty Tbk memiliki nilai yang rendah dimana perusahaan memiliki modal kerja yang lebih kecil dibanding dengan aset $\mathrm{X}_{2}$ yakni EBITA dimana aset lebih besar dibanding dengan laba sebelum beban bunga dan pajak yang didapat oleh perusahaan, hal ini dapat dinilai bahwa aset tidak secara efektif pemanfaatannya sehingga pendapatan rendah.

Analisis kebangkrutan dengan menggunakan metode Springatepada perusahaan Lippo Cikarang Tbk selama lima tahun dimulai dari tahun 2012 sampai dengan tahun 2016. Hasol analisis menunjukkan bahwa dari tahun 2013 sampai dengan tahun 2016 Lippo Cikarang Tbk berada di area non bangkrut, meskipun pada rasio EBITA yang dimiliki Lippo Cikarang Tbk memiliki nilai yang rendah dikarenakan aset lebih besar dibandingkan dengan laba sebelum beban bunga dan pajak tetapi perusahaan mampu mengendalikannya dengan memanfaatkan aset guna memenuhi kewajiban perusahaan.Perhitungan

menggunakan metode Springate yang dilakukan pada perusahanMNC Land Tbk. Hasil perhitungan memperlihatkan nahwa dari tahun 2013 hingga tahun 2016 perusahaan berada dalam kondisi baik, karena berada dalam area tidak berpotensi bangkrut.

\section{KESIMPULAN}

Penelitianini menggunakan alat analisis spirangate, maka dapat diketahui bagaimana kinerja keuangan perusahaan-perusahaa di industri properti dengan melihat kemungkinan perusahaan-perusahaan tersebut akan mengalami 
kebangkrutan atau tidaknya. membutuhkan modal dalam Berdasarkan perhitungan $z^{-}$menjalankan usahanya. Dan scoreyang diperoleh dari hasil perusahaan property umumnya perhitungan keempat rasio dibalikan memiliki hutang yang cukup besar dengan standar masing-masing rasio didalam menjalani usahanya. sesuai dengan ketentuan z-score, Penelitian lebih lanjut disarankan diketahui bahwa sebagian besar untuk melakukan analisa lebih lanjut perusahaan yang di prediksi mengalami kebangkrutan dimasa yang akan datang.

Penelitian ini menunjukan bahwa mayoritas dari kinerja perusahaan yang menjadi objek penelitian kurang baik, karena perusahaan secara mayoritas berada dalam zona tidak aman karena berpotensi mengalami kebangkrutan. Perusahaan masih kurang maksimal dalam pemanfaatan aset dan modal kerja dan perusahaan.

Perusahaan property adalah perusahaan yang banyak

\section{DAFTAR PUSTAKA}

Arikunto, Suharsimi, 2010: Prosedur Penelitian, Edisi Revisi, PT.RinekaCipta: Jakarta

terhadap struktur modal dan likuiditas perusahaan untuk melihat kinerja perusahaan lebih lanjut. Agar pengukuran potensi kebangkrutan terhadap jenis perusahaan properti dapat di analisa lebih akurat. Karena apabila perusahaan properti yang mengalami kebangkrutan akan menyebabkan permasalahan yang dapat meluas dalam perekonomian, karena perusahaan properti berkaitan dengan masyarakat luas dan berkaitan dengansector-sektor industri lainnya.

Brigham, E., dan Houston, J. 2010.Dasar - Dasar ManajemanKeuangan,Edisi I1Buku 1. Jakarta: Salemba Empat.

Darsono, Ashari, 2005: Pedoman Praktis Memahami Laporan Keuangan, Edisi 1,C.V. ANDI OFFSET (Penerbit ANDI): Yogyakarta.

Hani, Safrida, 2014: Teknik Analisa Laporan Keuangan, IN MEDIA.

Harahap, 2011: Analisis Kritis Atas Laporan Keuangan, Jakarta: PT. Raja Grafindo Persada

Hery, 2015: Analisis Laporan Keuangan. Jakarta: Bumi Aksara

Kasmir, 2011: Analisis Laporan Keuangan. Jakarta: PT. Raja Grafindo Persada.

Koto, Murviana, 2013: "Analisis PengaruhStruktur Modal Dan Profitabilitas Terhadap Nilai Resiko Dan Nilai Perusahaan (Studi Kasus Pada Perusahaan Properti Yang Terdaftar Di 
Bursa Efek Indonesia Tahun 2007-2011) ',. Tesis

Meiliawati dan Madiun. "Analisis Perbandingan Model Springate dan Altman Z-Score Terhadap Potensi Financial Distress (Studi Kasus Pada Perusahaan Sektor Kosmetik Yang Terdaftar Pada Bursa Efek Indonesia)'. Jurnal Akuntansi dan Pendidikan, Vol 5, No 1 April 2016

Munawir, S, 2010: Analisis Laporan Keuangan. (Cetakan ke-15), Yogyakarta: Liberty

Oktaviandri, Firli, dan Iradianty."Analisis Prediksi Kebangkrutan Dengan Model Altman, Springate, Ohlson, dan Grover pada PerusahaanDi Sektor Pertanian Bursa Efek Indonesia 2011-2015". Majalah Ilmiah UNIKOM Vol. 15, No. 1

Rudianto, 2012: Pengantar Akuntansi. Jakarta: Erlangga
Samryn I.M ,2011 : Pengantar Akuntansi Mudah Membuat Jurnal Dengan Pendekatan Siklus Transaksi. Edisi 1, Jakarta. Rajawali Pres.

Springate. Gordon L. V. 1978: PredictingthePossibilityofFailu re in a CanadianFirm. MBA Research Project Simon FraserUniversity

Susanti, Neneng. "Analisis Kebangkrutan dengan Menggunakan Metode Altman Z-ScoreSpringate dan Zmijewski pada Perusahaan Semen yang Terdaftar di BEI Periode 2011-2015". Jurnal Aplikasi MAnajemen, Vol 14, No. 4, 2016

Toto, Prihadi. 2011. Analisis Laporan Keuangan Teori dan Aplikasi, PPM. Jakarta.

Ida dan Santoso, Sandy. 2011. Analisis Kebangkrutan dengan Menggunakan Metode Springate. Dalam Media Bisnis, Maret. 